\title{
Inflammatory pseudotumour of the lung
}

\author{
Youri Kaitoukov MD ${ }^{1}$, George Rakovich $\mathrm{MD}^{1}$, Sylvain Trahan $\mathrm{MD}^{2}$, Jocelyn Grégoire $\mathrm{MD}^{3}$
}

Y Kaitoukov, G Rakovich, S Trahan, J Grégoire. Inflammatory pseudotumour of the lung. Can Respir J 2011;18(6):315-317.

Inflammatory pseudotumours of the lung are extremely rare. Their pathogenesis is controversial, their diagnosis is often difficult and their clinical behaviour may be unpredictable - ranging from benign to locally invasive, to metastatic in spite of an apparently 'benign' histology. A patient who presented with multiple recurrent lesions in the contralateral lung almost two years after the resection of a large primary tumour of the left upper lobe is reported.

Key Words: Inflammatory pseudotumour; Lung tumour

\section{LEARNING OBJECTIVES}

- Recognize the controversial nature of inflammatory pseudotumour of the lung.

- Understand that on rare occasions, inflammatory pseudotumour of the lung may behave in an aggressive fashion in spite of an apparently benign histology.

CanMEDS competency: Medical Expert

Pre-test

- What is the etiology of inflammatory pseudotumour of the lung?

- What characteristics of an inflammatory pseudotumour may be related to clinical behaviour?

\section{CASE PRESENTATION}

A 53-year-old woman was referred for a left upper lobe mass. She A was an active smoker with a 15 pack-year history, but otherwise denied any potentially noxious exposure. Her medical history included a left-sided pneumonia 10 years previously, at which time a parapneumonic effusion had been drained percutaneously. She complained of nonspecific chest pain for the previous three to four months. She did not exhibit any respiratory symptoms, fever or weight loss, and a review of systems was negative.

Imaging of the chest revealed a $5 \mathrm{~cm} \times 6 \mathrm{~cm}$ solid mass with illdefined borders in the apicoposterior segment of the left upper lobe, with a $4 \mathrm{~cm}$ area of contact with the chest wall (Figure 1). The lesion had a mean standard uptake value of 9.2 on fluorodeoxyglucose positron emission tomography. Bronchoscopy and a complete metastatic workup were negative.

Two transthoracic biopsies were nondiagnostic, while a third raised the possibility of inflammatory pseudotumour (IPT). We elected to perform an exploratory thoracotomy. Given the lack of a definitive diagnosis both pre- and intraoperatively, a left upper lobectomy was performed. The tumour was densely adherent to the parietal pleura, and dissection in an extrapleural plane was necessary. Blood loss was $2500 \mathrm{~mL}$ as a result of dense inflammatory adhesions. Mediastinal lymph nodes were negative. There were no postoperative complications and the patient was discharged in good condition on postoperative day 7. T cell, B cell and Hodgkin lymphomas were ruled out with immunohistochemistry. The final diagnosis was inflammatory pseudotumour (Figure 2). Resection margins were negative.

\section{Une pseudotumeur inflammatoire du poumon}

Les pseudotumeurs inflammatoires du poumon sont d'une extrême rareté. Leur pathogenèse est controversée, leur diagnostic est souvent difficile à poser et leur comportement clinique peut être imprévisible, passant de bénin à localement envahissant et à métastatique malgré une histologie d'apparence bénigne. Est exposé le cas d'un patient qui a présenté de multiples lésions récurrentes de la région controlatérale du poumon deux ans après la résection d'une grosse tumeur primaire du lobe supérieur gauche.

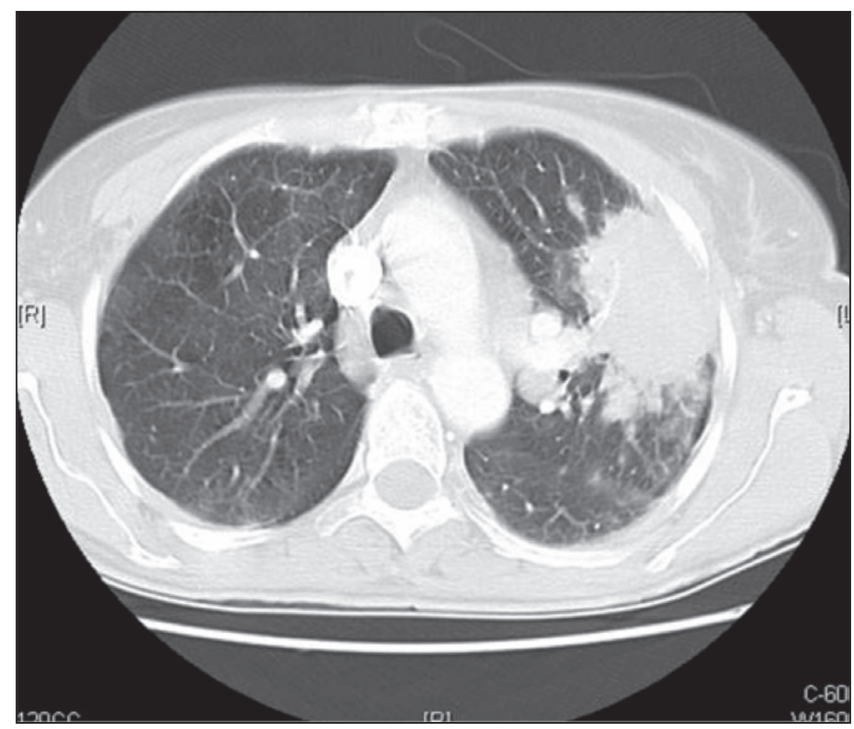

Figure 1) Computed tomography of the chest revealing a solid mass in the left upper lobe, with ill-defined borders and contact with the chest wall

On follow-up computed tomography (CT) scan at 19 months, five new nodules were discovered in the contralateral lung (Figures 2 and 3). The main lesion $(25 \mathrm{~mm} \times 16 \mathrm{~mm})$ was located in the middle lobe. Four other nodules of up to $1 \mathrm{~cm}$ in size were located in the right upper and right lower lobes, respectively. Recurrent inflammatory pseudotumour was suspected. All of the nodules detected on CT were amenable to a wedge resection. Negative $\mathrm{T}$ cell and $\mathrm{B}$ cell rearrangements, and immunohistochemical ruled out T cell, B cell and Hodgkin lymphomas. All five lesions demonstrated recurrent inflammatory pseudotumour.

\section{DISCUSSION}

IPT was first described by Brunn in 1939. It may occur anywhere in the body, but most commonly affects the lung and orbit (1). It accounts for less than $1 \%$ of lung resections (2-4). According to most authors, it represents a genuine neoplastic process, but some argue that it may represent an exaggerated inflammatory response to a variety of stimuli including minor trauma and infectious agents such as mycobacteria, Epstein-Barr virus, actinomyces, nocardia, mycoplasma and herpes simplex virus $(1,3)$. Immunoglobulin $\mathrm{G}_{4}$-related sclerosing disease is a

${ }^{1}$ Division of Thoracic Surgery, Hôpital Maisonneuve-Rosemont, University of Montreal, Montreal, Quebec; ${ }^{2}$ Division of Pathology; ${ }^{3}$ Division of Thoracic surgery, Institut Universitaire de Cardiologie et de Pneumologie (Hôpital Laval), Université Laval, Ste-Foy, Quebec

Correspondence: Dr George Rakovich, Division of Thoracic Surgery, Hôpital Maisonneuve-Rosemont, 5415 boulevard L'Assumption, Montreal,

Quebec H1T 2M4. Telephone 514-252-3822, fax 514-252-3894, e-mail george.rakovich@umontreal.ca 


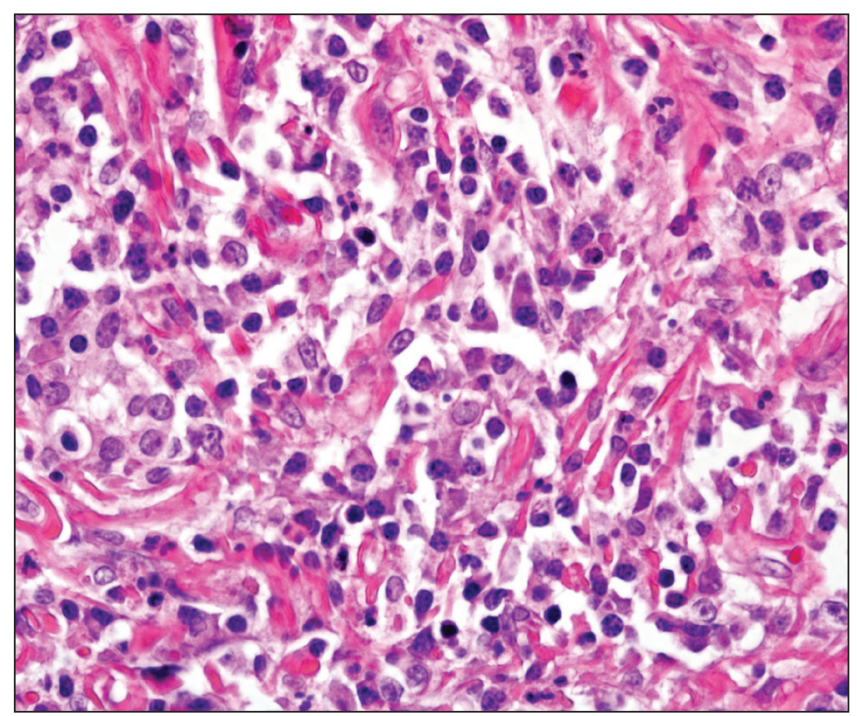

Figure 2) Inflammatory pseudotumour consisting of a mixed inflammatory infiltrate within a collagenous background (Hematoxylin and eosin stain, original magnification $\times 400$ )

recently described autoimmune process that histologically resembles IPT and may be related to the adult form of the disease $(5,6)$.

Most patients are younger than 40 years of age (4), and IPT is the most frequent lung tumour in children younger than 16 years of age (1). Common symptoms include cough, pain and fever, although up to $70 \%$ of patients are asymptomatic $(3,4)$. Imaging is nonspecific and often shows a solitary, well-circumscribed peripheral mass. Pathologically, these tumours are composed of a heterogeneous population of inflammatory and mesenchymal cells $(2,4)$. Definitive diagnosis of IPT may, therefore, be difficult by needle biopsies, even with multiple attempts (2-4). Important differential diagnostic considerations include sarcoma, malignant fibrous histiocytoma, lymphoma and malignant plasmacytoma (3). Although these lesions usually have an innocuous course, sarcomatous transformation has been described $(1,3)$. Occasionally, as in the patient we describe, IPT may show an aggressive behaviour with local invasion and metastasis even without actual 'malignant transformation' (1).

Steroids are the first line of treatment in cases of orbital tumours (1). Their role in the treatment of pulmonary lesions is limited, although there have been cases of complete regression after prolonged treatment (1-3). Chemotherapy and radiotherapy have been reported anecdotally with inconsistent results, and complete surgical resection remains the treatment of choice $(1,3,4)$. In general, completely resected lesions $<3 \mathrm{~cm}$ in diameter are associated with five-year survival rates of greater than $90 \%$ (7). Long-term survival decreases to below $50 \%$ for larger lesions $(>3 \mathrm{~cm}$ ) not amenable to complete resection (3). In children, it has been documented that lesions confined to the lung rarely recur, whereas those extending beyond the lung or affecting other organ systems have a 30 -fold increase in recurrence rates and a poor prognosis (8).

In our case, a large primary tumour was associated with multiple recurrences in the contralateral lung almost two years after resection, suggesting an aggressive form of the disease in spite of an apparently benign histology. Given the histological and clinical spectrum of IPTs, it may be questioned whether they represent a single disease process or encompass a group of heterogenous pathological entities. A better understanding of the nature of IPT may help in planning treatment and better defining the role of steroids and other adjuvant therapies.

\section{REFERENCES}

1. Das Narla L, Newman B, Spottswood SS, Narla S, Kolli R. Inflammatory pseudotumor. Radiographics 2003;23:719-29.

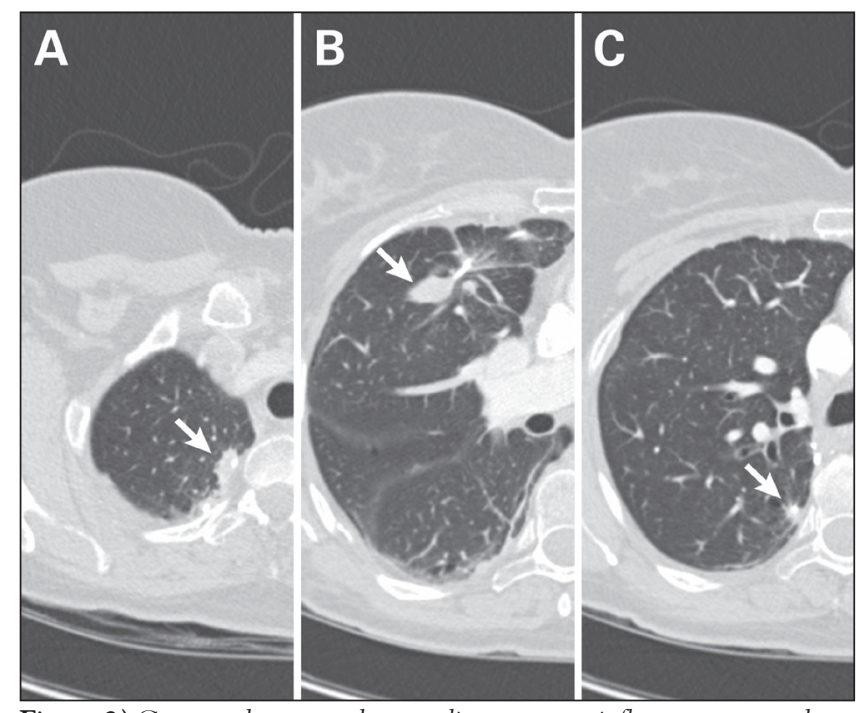

Figure 3) Computed tomography revealing recurrent inflammatory pseudotumour (arrows) in the right upper (A), middle (B) and lower (C) lobes

\section{Ishida T, Oka T, Nishino T, Tateishi M, Mitsudomi T,} Sugimachi K. Inflammatory pseudotumor of the lung in adults: Radiographic and clinicopathological analysis. Ann Thorac Surg 1989;48:90-5.

3. Melloni G, Carretta A, Ciriaco P, et al. Inflammatory pseudotumor of the lung in adults. Ann Thorac Surg 2005;79:426-32.

4. Kotoulas C, Konstantinou M, Fotinou M, Triggidou R, Papamichalis G, Lioulias A. Inflammatory pseudotumor of the lung: Our experience. Pneumon 2006;19:54-8.

5. Kamisawa T, Okamoto A. Autoimmune pancreatitis: Proposal of IgG4-related sclerosing disease. J Gastroenterol 2006;41:613-25.

6. Zen Y, Kitagawa S, Minato H, et al. $\operatorname{IgG}_{4}$-positive plasma cells in inflammatory pseudotumor (plasma cell granuloma) of the lung. Hum Pathol 2005;36:710-7.

7. Cerfolio RJ, Allen MS, Nascimento AG, et al. Inflammatory pseudotumors of the lung. Ann Thorac Surg 1999;67:933-6.

8. Janik JS, Janik JP, Lovell MA, Hendrickson RJ, Bensard DD, Greffe BS. Recurrent inflammatory pseudotumors in children. J Pediatr Surg 2003;38:1491-5.

\section{Post-test}

- What is the etiology of inflammatory pseudotumour of the lung?

Pathologically, inflammatory pseudotumours are composed of a heterogeneous population of inflammatory and mesenchymal cells. Most authors consider them to represent a genuine neoplastic process. However, some argue that they may in fact represent an exaggerated inflammatory response to a variety of stimuli, including trauma and infection.

- What characteristics of an inflammatory pseudotumour may be related to clinical behaviour?

These include size, whether the lesion is confined to the lung, and the possibility of complete surgical resection. Lesions smaller than $3 \mathrm{~cm}$ in diameter, confined to the lung, and amenable to complete resection are usually associated with a favourable prognosis. Larger lesions not amenable to complete resection, or those extending beyond the lung or affecting other organ systems are associated with high recurrence rates and a guarded prognosis.

\section{Additional reference}

Fabre D, Fadel E, Singhal S, et al. Complete resection of pulmonary inflammatory pseudotumors has excellent long-term prognosis. J Thorac Cardiovasc Surg 2009;137:435-40. 
The Canadian Respiratory Journal is now accepting submissions for a new Clinical-Pathologic Conference series. These will be based on case presentations that illustrate important learning issues involving diagnosis and/or management decisions, and should be supported by images from appropriately applied diagnostic and/or prognostic testing which could include: 1) Lung function tests; 2) Exercise testing; 3) X-rays or computed tomography scans; 4) Ultrasound (including endobronchial ultrasound); 5) Positron emission tomography scans; or 6) Bronchoscopy/thoracoscopy.

All case reports appearing in the Canadian Respiratory Journal will conform to this format and manuscripts should be structured as described in the Instructions to Authors. A maximum of four images can be submitted and the number of references should not usually exceed 10 . The submission will be peer reviewed and may be edited by our editorial team. 


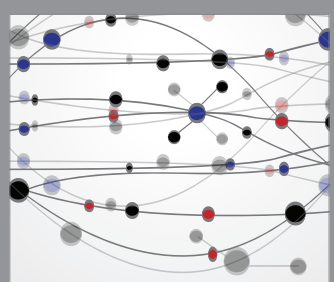

The Scientific World Journal
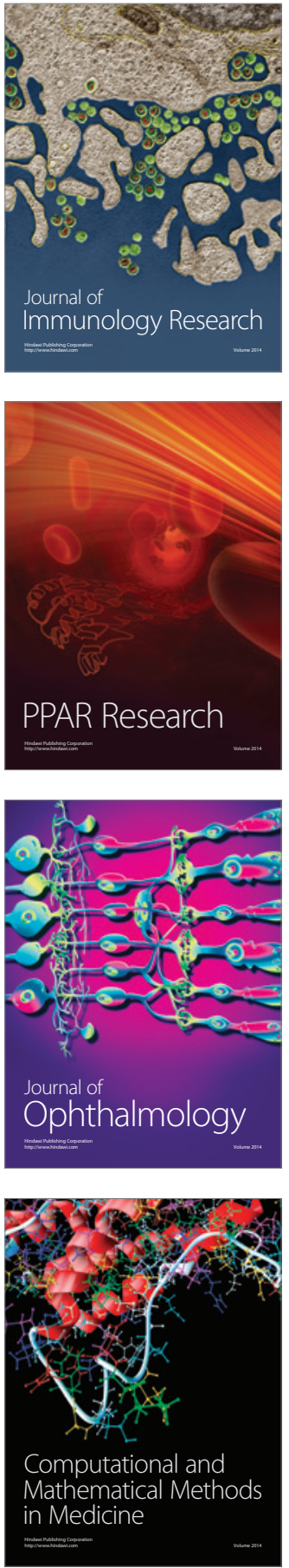

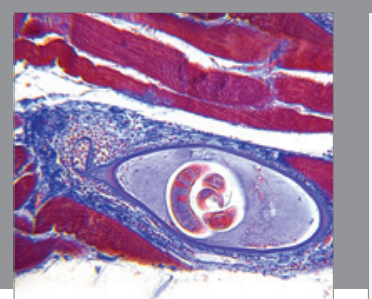

Gastroenterology Research and Practice

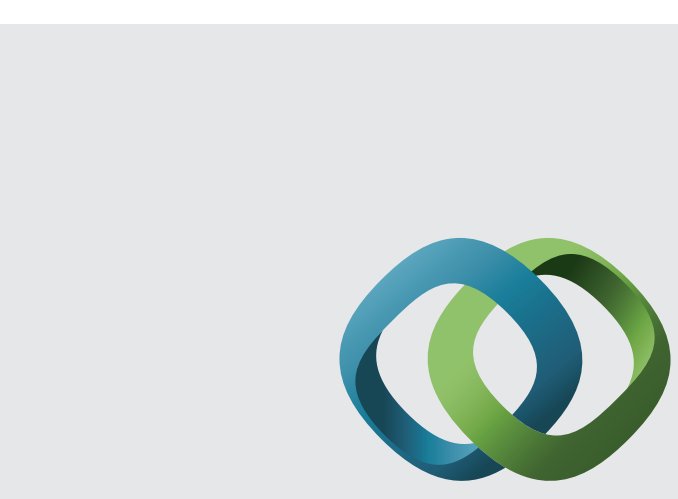

\section{Hindawi}

Submit your manuscripts at

http://www.hindawi.com
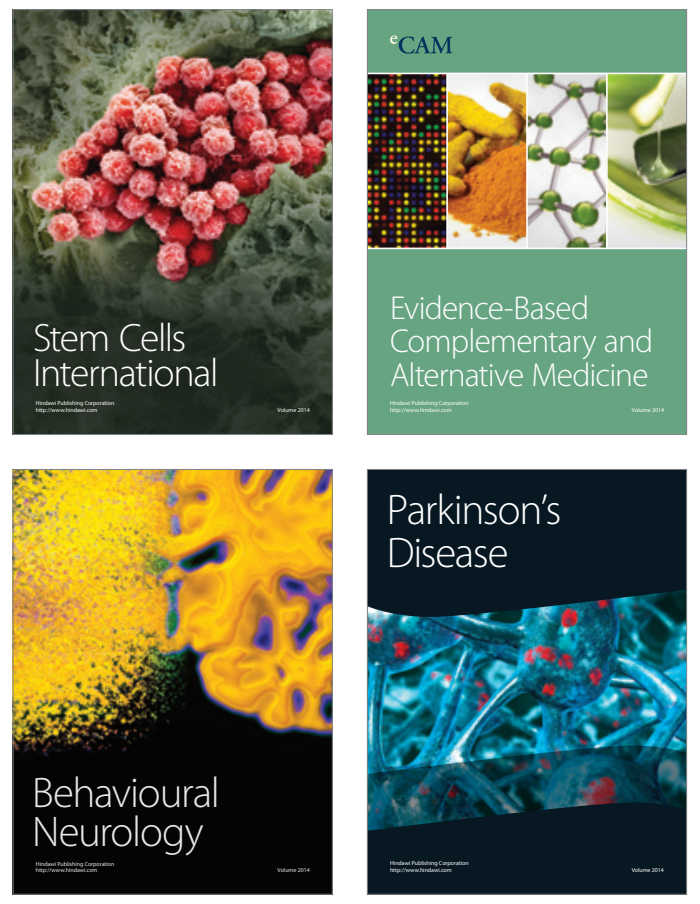
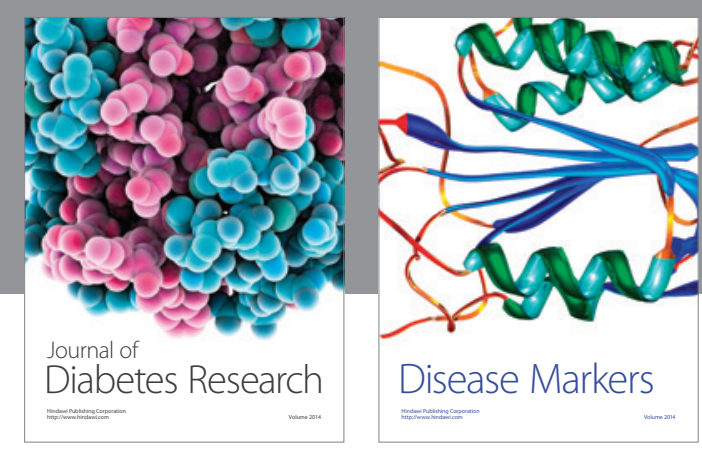

Disease Markers
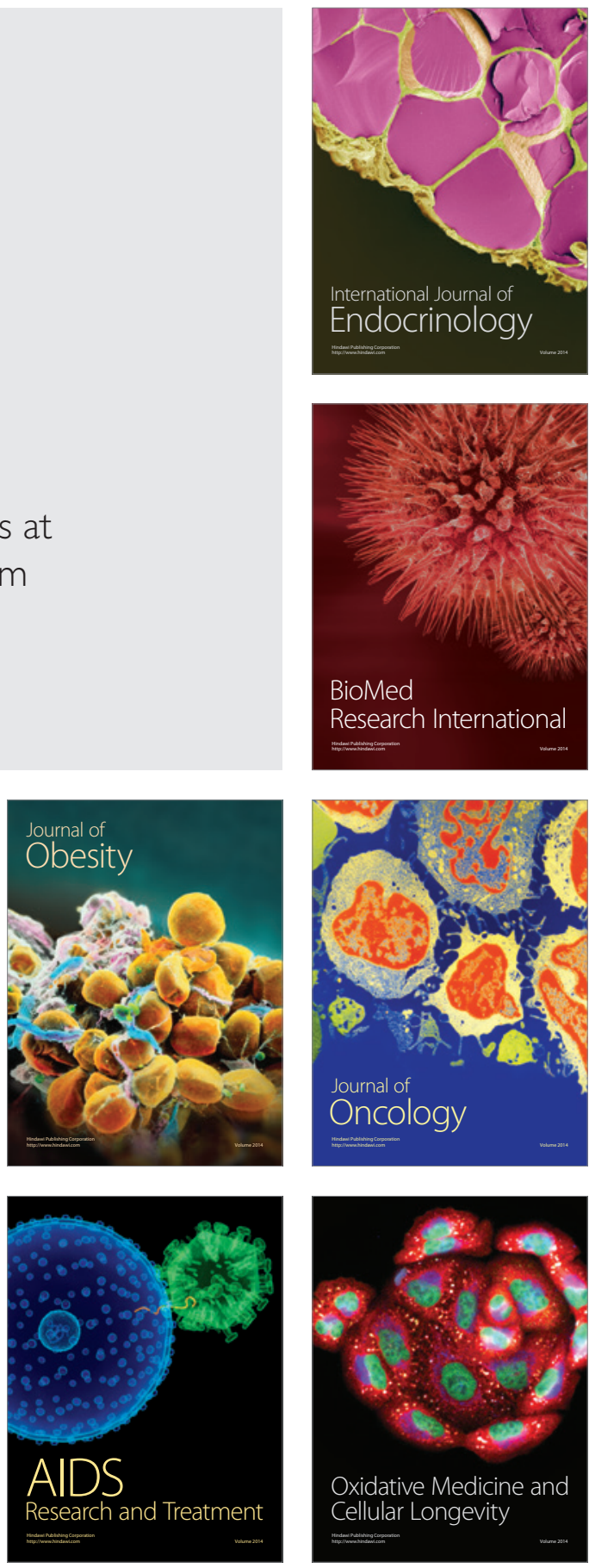